\title{
Prevalence and associated factors of vision loss in the South African National Health and Nutrition Examination Survey (SANHANES-1)
}

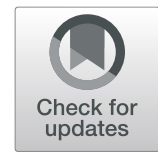

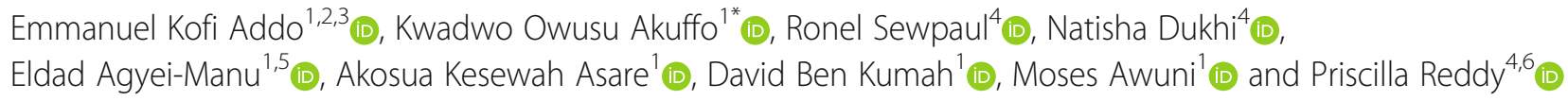

\begin{abstract}
Background: Vision loss is a major public health concern that significantly affects developing countries, including South Africa. Although existing literature have reported on the prevalence, causes, and impact of vision loss on the quality of life of affected individuals (children and adults) in parts of South Africa, there is no evidence of the prevalence and associated factors of vision loss in the general population. Hence, this study aimed to determine the prevalence of vision loss and its associated factors in South Africa using a population-based survey.

Methods: Secondary analyses were conducted using data from the South African National Health and Nutrition Examination Survey (SANHANES-1), a population-based national health survey conducted from 2011 to 2012. Vision loss was defined as presenting visual acuity (PVA) worse than Snellen 6/12 in the better eye. Visual acuity was assessed by clinicians and participants' subjective response to vision-related questions. Univariate and multiple logistic regression models were used to examine the association of the independent variables with vision loss.

Results: The analytic sample comprised 4346 individuals with a mean age of 39.1 years. Female sex accounted for $55.6 \%$ of the participants. The prevalence of vision loss among participants was 9.2\% (95\% Cl: 7.7-10.9). Older age (45-54 years, $\mathrm{OR}=2.99, p<0.001 ; 55-64$ years, $\mathrm{OR}=5.78, p<0.001$ and $\geq 65$ years, $\mathrm{OR}=5.12, p<0.001$ ), female sex $(\mathrm{OR}=1.50, p=0.016)$, and previous diabetes diagnosis $(\mathrm{OR}=2.28, p=0.001)$ were significantly associated with increased odds of vision loss. Further, secondary school education ( $O R=0.71, p=0.031)$, white ethnicity $(\mathrm{OR}=0.11$, $p=0.007)$, residing in Mpumalanga province $(\mathrm{OR}=0.12, p<0.001)$ and having never had an eye examination $(\mathrm{OR}=$ $0.56, p=0.003$ ) were significantly associated with reduced odds of vision loss.

Conclusion: Almost one in ten participants had vision loss. Adopting strategies targeted at reducing barriers to the utilization of eye care services will promote early detection and management of blinding conditions, and thereby, decrease the burden of vision loss in South Africa.
\end{abstract}

Keywords: Vision loss, Prevalence, SANHANES, Associated factors/determinants, Barriers, Disparities, Eyecare services, South Africa

\footnotetext{
* Correspondence: akuffokwadwoowusu@knust.edu.gh; koakuffo@gmail.com 'Department of Optometry and Visual Science, College of Science, Kwame Nkrumah University of Science and Technology, Kumasi, Ghana

Full list of author information is available at the end of the article
}

(C) The Author(s). 2021 Open Access This article is licensed under a Creative Commons Attribution 4.0 International License, which permits use, sharing, adaptation, distribution and reproduction in any medium or format, as long as you give appropriate credit to the original author(s) and the source, provide a link to the Creative Commons licence, and indicate if changes were made. The images or other third party material in this article are included in the article's Creative Commons licence, unless indicated otherwise in a credit line to the material. If material is not included in the article's Creative Commons licence and your intended use is not permitted by statutory regulation or exceeds the permitted use, you will need to obtain permission directly from the copyright holder. To view a copy of this licence, visit http://creativecommons.org/licenses/by/4.0/ The Creative Commons Public Domain Dedication waiver (http://creativecommons.org/publicdomain/zero/1.0/) applies to the data made available in this article, unless otherwise stated in a credit line to the data. 


\section{Background}

Vision loss (visual impairment and blindness) is a major public health concern worldwide [1-3] as it negatively impacts the quality of life [4-6], employment prospects, and socioeconomic status [4-6], and also, increases depression and anxiety in the elderly $[7,8]$. In children, vision loss limits potential maximization as it affects motor skills and emotional development [9], self-image $[10,11]$, academic prowess $[12,13]$, and social relations [14]. These challenges affect productivity, economic development, and also places an extreme burden on the country's healthcare systems $[15,16]$. Recent systematic review and meta-analysis estimates that about 253 million people in the world have vision loss; 36 million of which are blind, with 217 million having moderate or severe visual impairment [1-3]. Uncorrected refractive error $(49 \%)$ and cataract (26\%) are the principal causal factors of vision loss globally [1-3]. Notably, gender, age, and economic status influence the prevalence of vision loss worldwide. Thus, women (55\%), adults aged 50 years and above (80\%), and people living in developing countries (90\%) have an increased prevalence of vision loss $[1,2]$. A systematic review and meta-analysis published on the global burden of eye disease reports a prevalence of $2.90 \%$ of visual impairment and $0.48 \%$ of blindness in the world [1].

The distribution of vision loss is affected by both nonmodifiable risk factors (such as aging [17-19], genetics $[20,21]$, and ethnicity [18]) and modifiable risk factors (such as lifestyles [22, 23], and nutrition [24]). Recent progress in healthcare delivery has led to an upsurge in the life expectancy of the population worldwide [25]. Aging causes various structural and physiological changes that predispose adults to ocular morbidity (such as presbyopia, cataract, glaucoma, and age-related macular degeneration) [17-19]. Genetics has been shown to play a vital role in the etiology of some visual impairments. For instance, a positive family history of glaucoma and retinitis pigmentosa increases the risk of one developing the same conditions [20,21]. Also, ethnicity has been reported to be associated with vision loss; individuals of African descent are at an increased risk of developing glaucoma than Caucasians [18, 26]. Again, smoking has been shown to increase the risk of developing cataract [23] or causing early-onset or rapid progression of age-related macular degeneration (AMD) [22]. Additionally, reduced access to good nutrition is implicated in the development of visual impairment. For instance, inadequate intake of foods rich in micronutrients such as Vitamin A could lead to xerophthalmia, a type of Vitamin A deficiency that presents with symptoms of night blindness, and eventually blindness from corneal scarring when untreated [24]. Besides these factors, it is worth pointing out that socioeconomic status and demographic factors play a crucial role in the burden of vision loss [27].

Africa represents about $12 \%$ of the world's population; however, it contributes almost a fifth to the global burden of vision loss $[28,29]$. This heightened burden is occasioned by the perennial challenge of inadequate eye care professionals and their disproportionate distribution across nations, and the absence of eye care facilities in the much needed rural areas [30]. Southern sub-Saharan Africa comprising of five countries (including South Africa) have a crude prevalence of vision loss of $2.11 \%$, with the leading causes being uncorrected refractive error (0.84\%) and cataract $(0.59 \%)$ [1]. Previously, the National Guideline on Prevention of Blindness estimated a $0.75 \%$ prevalence of blindness in South Africa [31]. However, a recent study by Naidoo et al. reported a $0.90 \%$ prevalence of blindness; with cataract, refractive error, and glaucoma being the leading causes of vision loss in South Africa [32]. Of note, $80 \%$ of the population of South Africa suffer from extreme poverty, with the majority of the blind (80\%) living in rural communities [31].

Although existing literature have reported on the prevalence of visual loss/visual impairment in different districts/ provinces in South Africa, there is no evidence of the prevalence and associated factors of vision loss at the national level [31, 32]. Furthermore, a recent systematic review and meta-analysis by Naidoo et al. in 2020 showed that about half of the countries that constitute the subSaharan Africa region have no nationally representative data on the prevalence of vision loss [33]. Therefore, this study seeks to determine the prevalence of vision loss and its associated factors in South Africa using data from the South African National Health and Nutrition Examination Survey (SANHANES-1). This study will also inform policymakers, healthcare administrators, and eye care professionals on the need to revise public health policies, and further, promote efficient and equitable allocation of resources to alleviate the burden of vision loss in South Africa and sub-Saharan Africa at large.

\section{Methods \\ Study design}

Secondary analyses were conducted on data from the South African National Health and Nutrition Examination Survey (SANHANES-1), a population-based biobehavioural national survey conducted in 2011-2012 [34]. Data collection comprised interviews, general physical examination and biomarker analyses. Additional details of SANHANES-1 methodology and laboratory procedures are reported by Shisana et al. [34].

\section{Sociodemographic characteristics by province}

South Africa (SA) has nine (9) provinces, namely: Gauteng, KwaZulu-Natal, Western Cape, Eastern Cape, 
Limpopo, Mpumalanga, North West, Free State and Northern Cape. As of 2019, SA had a mid-year population estimates of 58.78 million with female sex accounting for nearly 30 million (51.2\%). Most of the SA population, about 15.2 million (25.8\%) and 11.3 million (19.2\%) resides in Gauteng (smallest province and yet highly urbanized) and KwaZulu-Natal respectively, with Northern Cape being the smallest province with a population of 1.26 million (2.2\%). Furthermore, Gauteng, Western Cape and KwaZulu-Natal provinces have large metropolitan urban areas, and together account for 58\% of the national population. Mpumalanga, North West, Limpopo, Free State, Northern Cape, and Eastern Cape contain large rural areas. Mpumalanga province has a large rural population and has the second highest provincial prevalence of adults with no formal education. In addition, about $28.8 \%$ of the SA population are younger than 15 years and mainly reside in Gauteng and KwaZulu-Natal. Of note, nearly $9 \%$ of the population are aged 60 years and above. Moreover, a third (17.8 million) of the SA population comprises the youth (aged 18-34 years), with nearly half residing in Gauteng (28.6\%) and KwaZulu-Natal (19.4\%). The Free State (4.7\%) and the Northern Cape $(2.0 \%)$ have the lowest proportions of youth [35].

\section{Sampling}

Multi-stage disproportionate, stratified cluster sampling was used to select households within enumeration areas (EAs) stratified by province and locality type. A total of 10,000 households were selected. Within the occupied households, 27,580 individuals of all ages were eligible to be interviewed and agreed to participate; out of whom $25,532(92.6 \%)$ completed the interview. Of the latter number, 12,025 (43.6\%) individuals volunteered to undergo medical examination. A total of 15,353 participants aged $\geq 15$ years completed the interview of which 7138 individuals aged $\geq 15$ years underwent a physical examination. Furthermore, 2048 of the eligible individuals did not consent to being interviewed, 13,507 of

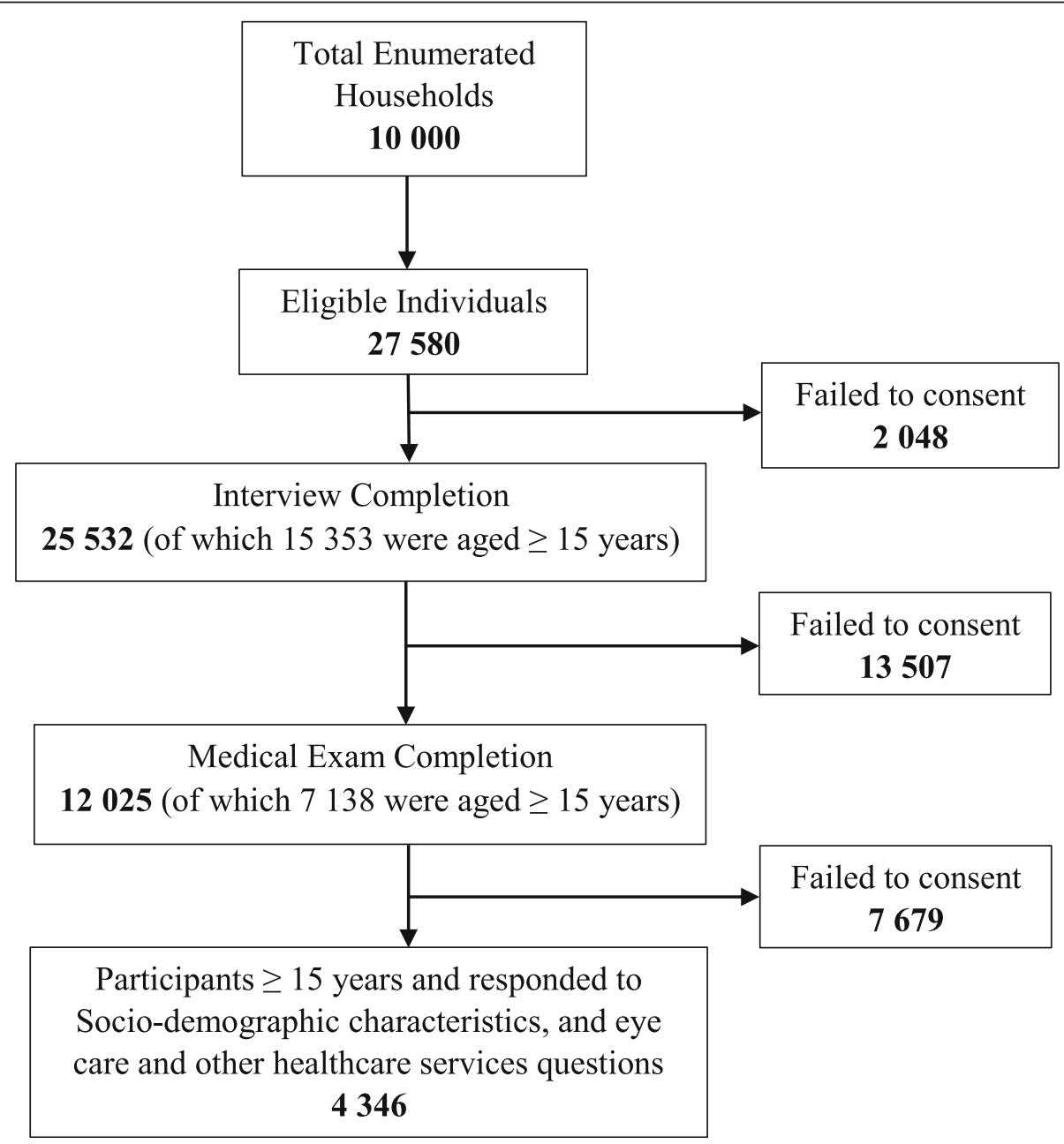

Fig. 1 Flowchart showing the derivation of the analytic sample 
those who completed the interview did not agree to undergo a physical examination and 7679 of those who completed the physical examination did not answer the questions on eye care and other healthcare services and thus, were excluded from this study (see Fig. 1).

\section{Visual examination}

Trained survey staff administered the interviews and clinical teams each comprising a registered nurse, a medical doctor, and clinical assistant, conducted the physical examinations. During the physical examination, the medical doctor assessed participants' visual acuity (using a Snellen chart) to determine whether participants had vision loss. Vision loss was defined as presenting visual acuity (PVA) worse than Snellen 6/12 in the better eye. Participants with vision loss were subsequently asked to provide self-reports on the kind(s) of vision-related difficulty they experienced; with response options being blurred vision, a need for more light, difficulty reading, loss of peripheral vision, difficulty driving at night, double vision, difficulty in distinguishing colours, straight lines looking wavy, and sensitivity to glare. In this study, 'blurred vision' was defined as participants' self-reported symptoms of inability to see objects sharply, especially during the execution of their normal day-to-day activities. 'A need for more light' encapsulates all forms of ocular pathology and refractive conditions that necessitate the need for an additional source of light to enable optimal visual functioning. 'Difficulty reading', 'loss of peripheral vision', 'difficulty driving at night', 'double vision', 'difficulty in distinguishing colours', 'straight lines looking wavy', and 'sensitivity to glare' were all based on participants' self-reported vision difficulty. The categories were not mutually exclusive, that is, a participant could experience multiple types of vision difficulties. All doctors employed in the study were trained in standardised procedures of measuring visual acuity.

\section{Ethical approval}

Ethical approval for the study was obtained from the Research Ethics Committee (REC) of the South African Human Sciences Research Council (HSRC) (REC number: $6 / 16 / 11 / 11$ ). The study adhered to the tenets of the Declaration of Helsinki. Written informed consent/ assent was obtained from all the survey participants. Written informed consent was also obtained from the parents or legal guardians of participants under the age of 18 years.

\section{Measures}

The primary outcome variable was vision loss, assessed by the medical doctor during the physical examination. Vision loss was defined as PVA worse than Snellen 6/12 in the better eye [36]. Independent variables, obtained from the interview, were sex, age group, ethnicity, education level, employment status, urban residence, province, diabetes diagnosis, and the number of years since their last eye examination. Ethnicity was reported according to Statistics South Africa's standard classification groups [37]. These variables were investigated because they have been found to be associated with vision loss in several studies [1, 2, 17-19, 32, 38-43]. In addition, age, sex, ethnicity and education have been found to confound the relationship between diabetes diagnosis and healthcare seeking on vision loss [42-46].

\section{Data analysis}

Data were analysed in Stata 15.0. (StataCorp, Texas, USA 2016). The analyses applied sample weights to adjust for unequal probabilities of selection and nonresponse. A total of 4346 individuals aged $\geq 15$ years underwent a physical examination and responded to the interview questions on socio-demographic characteristics and the use of eye care and other healthcare services. The prevalence of vision loss was presented by categories of the independent variables, and pairs of estimates were considered statistically different if their 95\% confidence intervals did not overlap. Among those who were assessed to have vision loss, the prevalence of the three most reported vision difficulties in this study, namely, blurred vision, a need for more light, and difficulty reading, were presented by the independent variables. Univariate and multiple logistic regression models were used to examine the association of the independent variables with the primary outcome; vision loss. Only the variables that were found to be significant in the univariate logistic regression were included in the multiple logistic regression model.

\section{Results}

\section{Description of the sample}

The mean age of all participants was 39.1 years (see Table 1). Two-thirds of the sample had a secondary school education, and $10 \%$ had tertiary education. Six percent $(6 \%)$ reported that they had been previously diagnosed with diabetes. Nearly a third of the participants (31.1\%) had ever had an eye examination, with $19.5 \%$ having had an eye examination within the last 2 years.

\section{Prevalence of vision loss}

Almost one in ten people (9.2 95\% CI: 7.7-10.9) were classified as having vision loss (see Table 2). Significantly more adults aged 45-54 years (16.9\%), 55-64 years (23.4\%) and $\geq 65$ years (21.1\%) experienced vision loss than those aged $15-44$ years (5.1\%). Vision loss was significantly higher among participants of Indian ethnicity (29.5\%) than in African (9.3\%), mixed-race (8.8\%), and 
Table 1 Description of the sample

\begin{tabular}{|c|c|c|}
\hline & $\mathrm{n}$ & $\%$ \\
\hline Total & 4346 & 100.0 \\
\hline Age (mean, S.D.) & 39.1 & 18.1 \\
\hline $15-44$ & 2712 & 72.1 \\
\hline $45-54$ & 671 & 13.1 \\
\hline $55-64$ & 527 & 8.2 \\
\hline$\geq 65$ & 436 & 6.6 \\
\hline \multicolumn{3}{|l|}{ Sex } \\
\hline Males & 1541 & 44.4 \\
\hline Females & 2805 & 55.6 \\
\hline \multicolumn{3}{|l|}{ Ethnicity } \\
\hline African & 3054 & 78.4 \\
\hline White & 87 & 8.4 \\
\hline Mixed race & 995 & 10.4 \\
\hline Indian/Asian & 210 & 2.8 \\
\hline \multicolumn{3}{|l|}{ Highest Education } \\
\hline No formal schooling/Gr0-7 & 1477 & 23.9 \\
\hline Grade 8-12 (or equivalent) & 2624 & 66.0 \\
\hline Higher education & 245 & 10.0 \\
\hline \multicolumn{3}{|l|}{ Employed } \\
\hline No & 3263 & 71.4 \\
\hline Yes & 1083 & 28.6 \\
\hline \multicolumn{3}{|l|}{ Urban/Rural residence } \\
\hline Rural & 1722 & 37.5 \\
\hline Urban & 2624 & 62.5 \\
\hline \multicolumn{3}{|l|}{ Province } \\
\hline Western Cape & 749 & 14.0 \\
\hline Eastern Cape & 594 & 12.7 \\
\hline Northern Cape & 326 & 2.8 \\
\hline Free State & 309 & 5.5 \\
\hline KwaZulu Natal & 678 & 19.4 \\
\hline North West & 382 & 5.1 \\
\hline Gauteng & 414 & 21.7 \\
\hline Mpumalanga & 518 & 7.8 \\
\hline Limpopo & 376 & 11.1 \\
\hline \multicolumn{3}{|l|}{ Self-reported diagnosis of diabetes } \\
\hline No previous diabetes diagnosis & 4030 & 94.0 \\
\hline Previous diabetes diagnosis & 316 & 6.0 \\
\hline \multicolumn{3}{|l|}{ Years since last eye examination } \\
\hline$\leq 2$ years & 761 & 19.5 \\
\hline $3-5$ years & 266 & 6.2 \\
\hline$>5$ years & 172 & 5.4 \\
\hline Never & 3147 & 68.9 \\
\hline
\end{tabular}


Table 1 Description of the sample (Continued)

\begin{tabular}{|c|c|c|}
\hline & $\mathrm{n}$ & $\%$ \\
\hline \multicolumn{3}{|c|}{ Do you use eyeglasses or contact lenses to see far away ${ }^{a}$} \\
\hline Yes & 468 & 13.8 \\
\hline No & 3852 & 86.2 \\
\hline \multicolumn{3}{|c|}{ Do you use eyeglasses or contact lenses to see up close ${ }^{a}$} \\
\hline Yes & 600 & 17.3 \\
\hline No & 3699 & 82.7 \\
\hline \multicolumn{3}{|c|}{ In the last 30 days, how difficult was it to see \& recognize an object or a person you know across the road (from a distance of about $20 \mathrm{~m}$ )? } \\
\hline None & 3367 & 83.8 \\
\hline Mild & 408 & 8.1 \\
\hline Moderate & 270 & 5.0 \\
\hline Severe & 162 & 3.1 \\
\hline \multicolumn{3}{|c|}{ In the last 30 days, how difficult was it to see $\&$ recognize an object at arm's length ${ }^{a}$} \\
\hline None & 3348 & 83.3 \\
\hline Mild & 452 & 8.7 \\
\hline Moderate & 256 & 5.0 \\
\hline Severe & 148 & 3.0 \\
\hline
\end{tabular}

$\mathrm{n}$, frequency; \%, percentage of the frequency; ${ }^{a}$ totals per category do not always add to overall total due to missing data and non-response (the number of missing observations for the last 4 variables; using visual aids to see far away, using visual aids to see up close, difficulty in seeing objects from across the road and difficulty in seeing objects at arm's length; were $26,47,139$, and 142 respectively)

white (2.2\%) ethnicities. Participants who had not completed secondary school (15.1\%) had significantly higher prevalence of vision loss than those who completed secondary $(7.5 \%)$ and tertiary (6.3\%) education. KwaZuluNatal province had the highest prevalence of vision loss (17.6\%) whereas, Mpumalanga province had the lowest (1.3\%). Vision loss was more than four times higher in participants who were diagnosed with diabetes (30.1\%) than those who were not diagnosed with diabetes (7.8\%). Vision loss was lower in participants who had never had an eye examination $(7.7 \%)$ than in those who had an eye examination within the preceding 2 years (13.3\%).

The three most prevalent types of vision difficulties reported by participants who were found to have vision loss were difficulty reading (56.2\%), blurred vision (42.3\%), and a need for more light (18.3\%) (see Table 3). Reading difficulty was significantly more prevalent among 45-54-year olds (74.9\%) than 15-44-year olds (45.5\%). Blurred vision was significantly higher among rural residents $(61.5 \%)$ than urban $(32.5 \%)$ residents. The prevalence of reporting a need for more light did not differ significantly between categories of the independent variables.

\section{Factors associated with vision loss}

The univariate logistic regression analysis showed that older age (45-54 years, odds ratio $(\mathrm{OR})=3.79, p<0.001$, $55-64$ years, $\mathrm{OR}=5.71, \mathrm{p}<0.001$ and $\geq 65$ years, $\mathrm{OR}=$ $5.00 p<0.001$ compared with 15-44 years), female sex $(\mathrm{OR}=1.57, p=0.003)$, Indian ethnicity $(\mathrm{OR}=4.09, p<$
0.001 compared with African ethnicity), residing in KwaZulu-Natal province (OR $=2.52, p=0.001$ compared with Western Cape province) and previous diabetes diagnosis $(\mathrm{OR}=5.07, p<0001)$ were significantly associated with experiencing vision loss (see Table 4). White ethnicity $(\mathrm{OR}=0.23, p=0.014$ compared with African ethnicity), higher education levels (secondary schooling, $\mathrm{OR}=0.46, p<0.001$ and tertiary education, $\mathrm{OR}=0.38$, $p=0.006$ compared with primary school or no formal schooling), residing in Mpumalanga province ( $\mathrm{OR}=0.16$, $p=0.001$ compared with Western Cape province) and having never had an eye examination $(\mathrm{OR}=0.54, \mathrm{p}=$ 0.001 compared with having had an eye examination within the preceding 2 years) were significantly associated with reduced odds of vision loss.

The multiple logistic regression model (see Table 4) included all the variables found to have a significant association with vision loss in the univariate logistic regression; namely, age group, sex, ethnicity, education, province, diabetes diagnosis, and number of years since last eye examination. In the multiple logistic regression, older age (45-54 years $\mathrm{OR}=2.99, p<0.001,55-64$ years $\mathrm{OR}=5.78, p<0.001$ and $\geq 65$ years $\mathrm{OR}=5.12, p<0.001$ compared with 15-44 years), female sex (OR $=1.50, p=$ $0.016)$, and previous diabetes diagnosis $(\mathrm{OR}=2.28, p=$ 0.001 ) were significantly associated with increased odds of vision loss. Secondary school education $(\mathrm{OR}=0.71$, $p=0.031$ compared with primary school or no formal education), white ethnicity $(\mathrm{OR}=0.11, p=0.007 \mathrm{com}$ pared with African ethnicity), residing in Mpumalanga 
Table 2 Prevalence of vision loss

\begin{tabular}{|c|c|c|c|}
\hline & \multicolumn{3}{|l|}{ Vision loss } \\
\hline & frequency & $\%$ & $95 \% \mathrm{Cl}$ \\
\hline Total & 481 & 9.2 & {$[7.7-10.9]$} \\
\hline \multicolumn{4}{|l|}{ Age (years) } \\
\hline $15-44$ & 111 & 5.1 & [3.8-6.8] \\
\hline $45-54$ & 117 & 16.9 & {$[12.4-22.5]$} \\
\hline $55-64$ & 140 & 23.4 & {$[17.0-31.3]$} \\
\hline$\geq 65$ & 113 & 21.1 & [14.8-29.3] \\
\hline \multicolumn{4}{|l|}{ Sex } \\
\hline Males & 160 & 7.2 & [5.6-9.1] \\
\hline Females & 321 & 10.8 & {$[8.8-13.2]$} \\
\hline \multicolumn{4}{|l|}{ Ethnicity } \\
\hline African & 290 & 9.3 & {$[7.5-11.3]$} \\
\hline White & 3 & 2.2 & {$[0.7-7.0]$} \\
\hline Mixed race & 118 & 8.8 & [5.9-12.7] \\
\hline Indian/Asian & 70 & 29.5 & {$[21.2-39.3]$} \\
\hline \multicolumn{4}{|l|}{ Highest Education } \\
\hline No formal schooling/Gr0-7 & 240 & 15.1 & [12.1-18.6] \\
\hline Grade 8-12 (or equivalent) & 215 & 7.5 & [5.9-9.4] \\
\hline Higher education & 26 & 6.3 & {$[3.4-11.4]$} \\
\hline \multicolumn{4}{|l|}{ Employed } \\
\hline No & 377 & 9.8 & {$[8.0-11.9]$} \\
\hline Yes & 104 & 7.7 & {$[5.5-10.7]$} \\
\hline \multicolumn{4}{|l|}{ Urban/Rural residence } \\
\hline Rural & 155 & 8.3 & {$[6.4-10.7]$} \\
\hline Urban & 326 & 9.7 & {$[7.7-12.2]$} \\
\hline \multicolumn{4}{|l|}{ Province } \\
\hline Western Cape & 87 & 7.8 & {$[5.2-11.7]$} \\
\hline Eastern Cape & 36 & 6.3 & {$[4.1-9.6]$} \\
\hline Northern Cape & 34 & 5.8 & {$[3.2-10.4]$} \\
\hline Free State & 41 & 9.9 & {$[5.3-17.8]$} \\
\hline KwaZulu Natal & 165 & 17.6 & [13.2-23.1] \\
\hline North West & 26 & 5.1 & {$[2.8-9.2]$} \\
\hline Gauteng & 54 & 9.2 & {$[5.6-14.7]$} \\
\hline Mpumalanga & 9 & 1.3 & {$[0.5-3.4]$} \\
\hline Limpopo & 29 & 7.3 & {$[4.3-12.0]$} \\
\hline \multicolumn{4}{|l|}{ Self-reported diagnosis of diabetes } \\
\hline No previous diabetes diagnosis & 386 & 7.8 & {$[6.5-9.5]$} \\
\hline Previous diabetes diagnosis & 95 & 30.1 & {$[22.4-39.3]$} \\
\hline \multicolumn{4}{|l|}{ Years since last eye examination } \\
\hline$\leq 2$ years & 158 & 13.3 & {$[9.7-18.0]$} \\
\hline $3-5$ years & 38 & 13.2 & {$[8.1-20.9]$} \\
\hline$>5$ years & 27 & 8.8 & {$[4.6-16.4]$} \\
\hline Never & 258 & 7.7 & {$[6.2-9.4]$} \\
\hline
\end{tabular}


Table 2 Prevalence of vision loss (Continued)

\begin{tabular}{|c|c|c|c|}
\hline & \multicolumn{3}{|l|}{ Vision loss } \\
\hline & frequency & $\%$ & $95 \% \mathrm{Cl}$ \\
\hline \multicolumn{4}{|c|}{ Do you use eyeglasses or contact lenses to see far awayt } \\
\hline Yes & 111 & 14.3 & {$[9.3-21.2]$} \\
\hline No & 367 & 8.4 & {$[7.0-10.1]$} \\
\hline \multicolumn{4}{|c|}{ Do you use eyeglasses or contact lenses to see up closet } \\
\hline Yes & 126 & 12.4 & {$[8.2-18.2]$} \\
\hline No & 348 & 8.5 & {$[7.1-10.2]$} \\
\hline \multicolumn{4}{|c|}{ In the last 30 days, how difficult was it to see \& recognize an object or a person you know across the road (from a distance of about 20 m)? } \\
\hline None & 269 & 6.3 & {$[5.1-7.7]$} \\
\hline Mild & 84 & 19.1 & [13.0-27.0] \\
\hline Moderate & 63 & 24.1 & [17.7-31.8] \\
\hline Severe & 49 & 36.3 & {$[23.0-52.0]$} \\
\hline \multicolumn{4}{|c|}{ In the last 30 days, how difficult was it to see \& recognize an object at arm's length $\dagger$} \\
\hline None & 260 & 6.3 & {$[5.1-7.7]$} \\
\hline Mild & 98 & 18 & {$[13.1-24.2]$} \\
\hline Moderate & 62 & 23.4 & {$[16.9-31.4]$} \\
\hline Severe & 46 & 40 & {$[26.0-55.8]$} \\
\hline
\end{tabular}

$\%$, percentage of frequency; Cl Confidence Interval

province $(\mathrm{OR}=0.12, p<0.001)$ and having never had an eye examination $(\mathrm{OR}=0.56, p=0.003$ compared with having had an eye examination within the preceding 2 years) were significantly associated with reduced odds of vision loss.

\section{Discussion}

In this study, we investigated the prevalence of vision loss among South Africans using data from the South African National Health and Nutrition Examination Survey (SANHANES-1), a population-based bio-behavioural national survey conducted in 2011-2012. The results showed that nearly one in ten of all the participants had vision loss. In the multiple logistic regression, which adjusted for age, sex, ethnicity, education, province, previous diabetes diagnosis and number of years since last eye examination, older age, female sex, and previous diabetes diagnosis were found to be associated with higher odds of vision loss whereas, white ethnicity, formal education (completion of secondary or tertiary education), residing in Mpumalanga province, and having never had an eye examination were significantly associated with lower odds of vision loss.

Naturally, aging presents with various structural and functional changes that make one susceptible to ocular morbidity. As individuals age, eye diseases (cataract, glaucoma, age-related macular degeneration, and presbyopia) occur and consequently lead to vision loss (if untreated) [17-19]. Globally, the prevalence of vision loss increases with age $[1,2]$. Thus, with the world population growth on the ascendency and the elderly having a longer lifespan, eye care needs for the elderly is expected to rise. Our result is consistent with studies among Nigerian [38], Chinese American [47], and Iranian [48] populations, which shows older age to be significantly associated with higher odds of vision loss. Similar studies in various provinces in South Africa have shown similar findings [27, 41]. Besides differences in the methodology of the various studies, there is a general positive association between increasing age and the odds of having vision loss.

In this study, female sex was noted to be significantly associated with the prevalence of vision loss. Generally, women are known to be at increased risk of vision loss than men [39, 49, 50]. Women's increased susceptibility to vision loss may be partly due to their higher life expectancy than men $[51,52]$. Although the regression analysis adjusted for age, the adjustment may have been partial, because the age-groups used may have needed to be more finely disaggregated to distinguish participants older than 65 years. Evidence from studies show that variations in the composition of hormones and chromosomes in men and women account for the differences in longevity [53]. For instance, women appear to have more subcutaneous fat, whereas men have more visceral fat, which is predictive of cardiovascular disease [53]. This distribution is impacted by oestrogen, and the additional $\mathrm{X}$ chromosome predominantly found in women. Thus, with women having a longer lifespan than men in South Africa (67.7 years as compared to 61.5 years), it is 
Table 3 Self-reported vision difficulties among participants who had vision loss

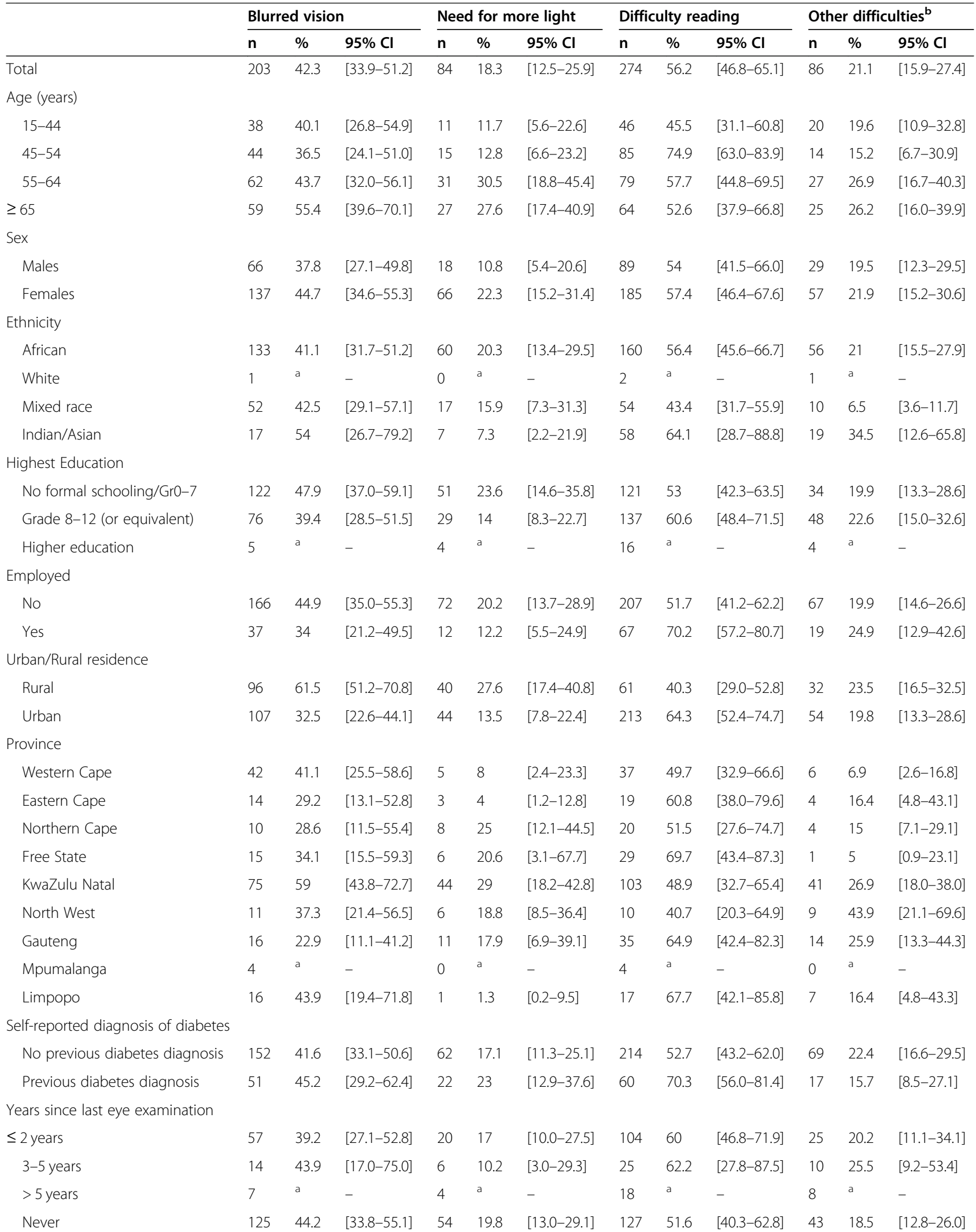


Table 3 Self-reported vision difficulties among participants who had vision loss (Continued)

\begin{tabular}{|c|c|c|c|c|c|c|c|c|c|c|c|c|}
\hline & \multicolumn{3}{|c|}{ Blurred vision } & \multicolumn{3}{|c|}{ Need for more light } & \multicolumn{3}{|c|}{ Difficulty reading } & \multicolumn{3}{|c|}{ Other difficulties $^{b}$} \\
\hline & $\mathrm{n}$ & $\%$ & $95 \% \mathrm{Cl}$ & $\mathrm{n}$ & $\%$ & $95 \% \mathrm{Cl}$ & $\mathrm{n}$ & $\%$ & $95 \% \mathrm{Cl}$ & $\mathrm{n}$ & $\%$ & $95 \% \mathrm{Cl}$ \\
\hline \multicolumn{13}{|c|}{ Do you use eyeglasses or contact lenses to see far away ${ }^{c}$} \\
\hline Yes & 42 & 38.5 & {$[22.7-57.1]$} & 12 & 14.5 & {$[7.1-27.6]$} & 79 & 72.9 & {$[55.9-85.1]$} & 26 & 30.7 & {$[16.8-49.3]$} \\
\hline No & 161 & 43.5 & {$[34.6-52.8]$} & 72 & 19.4 & {$[12.8-28.2]$} & 192 & 51.5 & {$[41.7-61.1]$} & 60 & 18.6 & {$[13.7-24.7]$} \\
\hline \multicolumn{13}{|c|}{ Do you use eyeglasses or contact lenses to see up close $^{c}$} \\
\hline Yes & 44 & 35.1 & {$[20.4-53.2]$} & 18 & 14.4 & {$[7.3-26.4]$} & 98 & 77 & {$[60.7-87.8]$} & 27 & 27.8 & {$[15.0-5.7]$} \\
\hline No & 158 & 44.8 & {$[35.8-54.2]$} & 66 & 19.7 & {$[13.1-28.5]$} & 170 & 49.5 & {$[39.5-59.6]$} & 59 & 19.3 & {$[14.2-25.7]$} \\
\hline
\end{tabular}

In the last 30 days, how difficult was it to see $\&$ recognize an object or a person you know across the road (from a distance of about $20 \mathrm{~m}$ )? ${ }^{c}$

$\begin{array}{lllllllllllll}\text { None } & 114 & 39.9 & {[30.5-50.1]} & 45 & 17.7 & {[11.5-26.2]} & 150 & 56.4 & {[46.1-66.3]} & 42 & 17.2 & {[11.3-25.2]} \\ \text { Mild } & 31 & 35.6 & {[21.3-53.0]} & 23 & 27.1 & {[14.8-44.3]} & 53 & 60.6 & {[40.5-77.7]} & 19 & 23.9 & {[14.3-37.0]} \\ \text { Moderate } & 30 & 49.1 & {[32.6-65.9]} & 8 & 17 & {[7.8-33.1]} & 34 & 52.7 & {[35.4-69.4]} & 10 & 23.2 & {[12.5-38.9]} \\ \text { Severe } & 24 & 57.7 & {[32.9-79.1]} & 5 & 7.3 & {[2.5-19.6]} & 26 & 50.1 & {[25.5-74.6]} & 12 & 32 & {[12.9-60.0]}\end{array}$

In the last 30 days, how difficult was it to see \& recognize an object at arm's length ${ }^{c}$

\begin{tabular}{lllllllllllll} 
None & 116 & 40.6 & {$[31.0-51.0]$} & 47 & 18 & {$[11.6-26.9]$} & 142 & 55.5 & {$[45.1-65.4]$} & 40 & 17.4 & {$[11.1-26.3]$} \\
Mild & 32 & 37 & {$[21.4-55.9]$} & 21 & 25.8 & {$[14.2-42.2]$} & 61 & 56.8 & {$[39.4-72.6]$} & 23 & 24.1 & {$[13.3-39.6]$} \\
Moderate & 29 & 47 & {$[31.4-63.2]$} & 10 & 19.8 & {$[9.4-37.0]$} & 36 & 56.5 & {$[38.2-73.1]$} & 8 & 21.4 & {$[11.0-37.5]$} \\
Severe & 22 & 53.4 & {$[29.3-76.0]$} & 3 & 5.2 & {$[1.5-16.1]$} & 25 & 56.5 & {$[31.0-79.0]$} & 12 & 31.2 & {$[12.9-58.2]$} \\
\hline
\end{tabular}

$\mathrm{n}$, frequency; \%, percentage of the frequency; $\mathrm{Cl}$ Confidence Interval; ${ }^{\mathrm{a}} \mathrm{n}<30$; ${ }^{\mathrm{b}}$ one or more of the following: loss of peripheral vision, difficulty driving at night, double vision, difficulty in distinguishing colours, straight lines looking wavy, and sensitivity to glare; ' totals per category do not always add to overall total due to missing data and non-response (the number of missing observations for the last 4 variables; using visual aids to see far away, using visual aids to see up close, difficulty in seeing objects from across the road and difficulty in seeing objects at arm's length; were $3,7,16$, and 15 respectively)

expected that they may have a higher risk of developing ocular morbidities than men [35]. The gender disparity regarding access to medical care services, especially in some developing countries, could account for the higher prevalence of vision loss in women [54]. Thus, the existence of socio-economic and cultural disparities between men and women in developing countries contribute to women having higher prevalence of vision loss. For instance, women may have restricted movement, their eye care needs may not be deemed as urgent compared to males, and they may not have the financial ability to pay for eye care services. These situations deny women of the opportunity to access healthcare, and thus, makes it difficult to detect and prevent ocular diseases among women in the early stages [55]. This finding is consistent with studies in South Africa [32, 41], Nigeria [38, 40, 54], Iran [48], and Malaysia [56]. This behoves policymakers to create awareness and avenues for women to engage in meaningful and productive ventures with reasonable remuneration. Health education and promotion can be tailored for women, to enable them to be more proactive in their healthcare seeking behaviours, empower them to make informed decisions on matters pertaining to their health and increase their accessibility to health care services.

Interestingly, higher education levels (completion of secondary school or tertiary education) remained significantly associated with a decreased prevalence of vision loss in this study. Notably, not only does educational knowledge shape an individual's employment prospects (i.e., better remuneration, favorable working conditions, and better health-related benefits), but it also empowers them to make informed decisions regarding their health (i.e., having a higher demand for good sight and easy accessibility to eye care services) than the people without formal education $[57,58]$. On the contrary, not having access to formal education may be associated with a higher use of traditional medicine [59]. This means has proven unsuccessful over time and is known to exacerbate the burden of vision loss. Furthermore, it is worth mentioning that people who do not have access to formal education are more likely to have difficulty obtaining healthcare, as poverty impedes both access to education and access to healthcare [27, 60]. A study by Gilbert et al. in Nigeria reported that majority of the residents without formal education in rural communities resorted to couching (a traditional treatment of cataract by dislocating the cataractous lens into either the anterior segment or the posterior segment with no intraocular lens implantation), which rendered close to half of the individuals who had undergone couching blind [59]. Our finding is consistent with studies in India [61, 62], China [63, 64], and Nepal [65], which indicates the need for the institution of practical measures to promote health education regarding ocular health, especially in rural communities across the nation. 
Table 4 Factors associated with vision loss

\begin{tabular}{|c|c|c|c|c|c|c|}
\hline \multirow{3}{*}{$\begin{array}{l}\text { Age (years) } \\
\end{array}$} & \multicolumn{3}{|c|}{ Univariate logistic regression } & \multicolumn{3}{|c|}{ Multiple logistic regression $^{\text {b }}$} \\
\hline & Crude OR & 95\% Cl (Crude OR) & $\overline{p \text {-value }}$ & \multirow[t]{2}{*}{ AOR } & \multirow[t]{2}{*}{$95 \% \mathrm{Cl}(\mathrm{AOR})$} & \multirow[t]{2}{*}{$p$-value } \\
\hline & & & & & & \\
\hline $15-44$ & ref & - & - & ref & - & - \\
\hline $45-54$ & $3.79^{\mathrm{a}}$ & [2.44-5.87] & $<0.001$ & $2.99^{\mathrm{a}}$ & {$[1.93-4.62]$} & $<0.001$ \\
\hline $55-64$ & $5.71^{\mathrm{a}}$ & {$[3.5-9.31]$} & $<0.001$ & $5.78^{a}$ & {$[3.73-8.98]$} & $<0.001$ \\
\hline$\geq 65$ & $5.00^{\mathrm{a}}$ & {$[2.97-8.43]$} & $<0.001$ & $5.12^{a}$ & {$[3.16-8.27]$} & $<0.001$ \\
\hline \multicolumn{7}{|l|}{ Sex } \\
\hline Males & ref & - & - & ref & - & - \\
\hline Females & $1.57^{\mathrm{a}}$ & {$[1.17-2.1]$} & 0.003 & $1.50^{\mathrm{a}}$ & {$[1.08-2.08]$} & 0.016 \\
\hline \multicolumn{7}{|l|}{ Ethnicity } \\
\hline African & ref & - & - & ref & - & - \\
\hline White & $0.23^{a}$ & {$[0.07-0.74]$} & 0.014 & $0.11^{\mathrm{a}}$ & {$[0.02-0.56]$} & 0.007 \\
\hline Mixed race & 0.94 & {$[0.58-1.51]$} & 0.801 & 0.82 & {$[0.43-1.56]$} & 0.541 \\
\hline Indian/Asian & $4.09^{a}$ & {$[2.5-6.71]$} & $<0.001$ & 1.74 & {$[0.88-3.45]$} & 0.112 \\
\hline \multicolumn{7}{|l|}{ Highest Education } \\
\hline No formal schooling/Gr0-7 & ref & - & - & ref & - & - \\
\hline Grade 8-12 (or equivalent) & $0.46^{\mathrm{a}}$ & {$[0.33-0.63]$} & $<0.001$ & $0.71^{a}$ & {$[0.52-0.97]$} & 0.031 \\
\hline Higher education & $0.38^{a}$ & {$[0.19-0.75]$} & 0.006 & 0.48 & {$[0.22-1.03]$} & 0.059 \\
\hline \multicolumn{7}{|l|}{ Employed } \\
\hline No & ref & - & - & & & \\
\hline Yes & 0.77 & {$[0.51-1.16]$} & 0.207 & & & \\
\hline \multicolumn{7}{|l|}{ Urban or rural residence } \\
\hline Rural & ref & - & - & & & \\
\hline Urban & 1.19 & {$[0.81-1.75]$} & 0.382 & & & \\
\hline \multicolumn{7}{|l|}{ Province } \\
\hline Western Cape & ref & - & - & ref & - & - \\
\hline Eastern Cape & 0.79 & {$[0.42-1.49]$} & 0.461 & 0.63 & {$[0.28-1.41]$} & 0.263 \\
\hline Northern Cape & 0.73 & {$[0.34-1.57]$} & 0.419 & 0.62 & {$[0.28-1.37]$} & 0.240 \\
\hline Free State & 1.30 & {$[0.58-2.9]$} & 0.526 & 1.07 & {$[0.42-2.71]$} & 0.894 \\
\hline KwaZulu Natal & $2.52^{\mathrm{a}}$ & {$[1.44-4.4]$} & 0.001 & 1.86 & {$[0.88-3.9]$} & 0.102 \\
\hline North West & 0.63 & {$[0.29-1.36]$} & 0.239 & 0.43 & {$[0.17-1.11]$} & 0.082 \\
\hline Gauteng & 1.19 & [0.59-2.38] & 0.631 & 1.07 & {$[0.5-2.32]$} & 0.855 \\
\hline Mpumalanga & $0.16^{a}$ & {$[0.06-0.45]$} & 0.001 & $0.12^{a}$ & {$[0.04-0.36]$} & $<0.001$ \\
\hline Limpopo & 0.92 & {$[0.45-1.87]$} & 0.818 & 0.78 & {$[0.26-2.35]$} & 0.662 \\
\hline \multicolumn{7}{|l|}{ Diabetes diagnosis } \\
\hline No previous diagnosis of diabetes & Ref & - & - & ref & - & - \\
\hline Previous diagnosis of diabetes & $5.07^{\mathrm{a}}$ & {$[3.32-7.73]$} & $<0.001$ & $2.28^{a}$ & {$[1.38-3.75]$} & 0.001 \\
\hline \multicolumn{7}{|l|}{ Years since last eye examination } \\
\hline$\leq 2$ years & Ref & - & - & ref & - & - \\
\hline $3-5$ years & 0.99 & {$[0.5-1.97]$} & 0.980 & 0.85 & [0.39-1.88] & 0.690 \\
\hline$>5$ years & 0.63 & [0.31-1.28] & 0.199 & 0.66 & {$[0.3-1.42]$} & 0.285 \\
\hline Never & $0.54^{a}$ & {$[0.37-0.79]$} & 0.001 & $0.56^{a}$ & [0.38-0.82] & 0.003 \\
\hline
\end{tabular}

ref, reference; ${ }^{a}$ statistically significant; $O R$ Odds ratio, $A O R$ Adjusted odds ratio, $\mathrm{Cl}$ Confidence Interval. ${ }^{\mathrm{b}}$ The following variables were included in the multiple logistic regression model: age group, sex, ethnicity, education, province, diabetes diagnosis, and number of years since last eye examination 
Despite the government's efforts in reducing inequity and improving access to health care, there still exist disparities in health status and accessibility to healthcare services, including eye care in South Africa [66]. Most eye care providers (ophthalmologists and optometrists) in South Africa are with the private sector in the urban areas of the provinces, leaving minimal numbers in the public sector to cater for the majority of the populace [67]. Hence, with a considerable proportion of the people in poverty living in rural areas [68], coupled with the differences in the distribution of healthcare personnel, and the unavailability of eye care service providers in the rural areas as compared to the urban communities, make access to health care services extremely challenging and thus, may lead to increased prevalence of vision loss in the rural areas [69-72]. Furthermore, blurred vision and difficulty reading were the main contributors to vision loss in our study. This could be attributable to refractive errors and presbyopia, which could be easily corrected with prescription glasses [1-3, 41, 42, $71,73,74]$. However, barriers such as the cost of transport and high prices of eye care services, as well as prescription spectacles, deter the people in poverty from patronizing the services of eye care professionals [75]. Therefore, a timely intervention by the government and stakeholders of healthcare through the training of adequate eye health workers and the provision of the necessary health equipment will promote the efficient and effective utilization of eye care services. This measure will decrease the burden of vision loss and its impact on the quality of life of affected individuals.

In recent times, the National Prevention of Blindness Program has outlined some health guidelines aimed at coordinating and providing support towards blindness prevention, improving access to primary eye care, and promoting the rights of the blind in South Africa [31]. These eye health guidelines are mainly curative, and thus, there is an absence of an integrated eye health promotional policy and a dedicated directorate to monitor and evaluate eye health promotional activities in South Africa [76]. Although the government collaborates with both local and international agencies to address these gaps, these collaborations are short-lived due to the financial constraints involved. Further, a prospective study by Lilian et al., which assessed the primary eye care services in three South African districts, showed the need for introducing health system strengthening (HSS) package in primary eye care delivery. The study revealed that HSS enhanced organizational care and clinical practice [77]. Therefore, to curb the increasing occurrence of people going needlessly blind or having visual impairments, it is imperative that policymakers institute measures that aim to integrate ocular health promotional activities in the primary health care system.
Our study identified self-reported visual difficulty as a vital component of vision loss. Thus, a considerable number of participants (with or without spectacle use) had vision loss. This challenge could partly result from the unavailability of service providers within the needed catchment areas as well as inadequate education about the relevance of optical correction in optimizing sight [69-71]. Hence, participants resort to adaptive means of vision enhancement such as increasing illumination, increasing of font size, and reading at arm's length, which could account for the low utilization of spectacles. This explains why most of the participants had no difficulty in recognizing objects at arm's length or persons across the street. This finding is consistent with a study by Naidoo et al., which aimed at investigating the prevalence of self-reported vision difficulty in some regions of South Africa [42]. Therefore, appropriate implementation of cost-effective eye health screening programs by policymakers is paramount in reducing the burden of vision loss, especially in deprived regions in South Africa.

Moreover, the absence of simple, effective screening equipment for diabetic retinopathy in the various primary healthcare in South Africa could account for the four-fold increase in odds of vision loss among diabetics in this study $[76,78,79]$. Thus, the majority of patients only sought medical care once retinopathies have already developed, and vision affected considerably [80]. A pilot screening study with a mobile fundus camera in Cape Town proved useful as a single technician could screen about 10,000 patients in a year [80]. However, a study by $\mathrm{Tu}$ et al. reported poor cost-effectiveness of digital photography screening among individuals with diabetic retinopathy in the United Kingdom, and this primarily resulted from poor compliance rates [81]. Hence, the use of a digital fundus camera as a screening tool is not wholly accepted by practitioners. Therefore, with the increasing trend of diabetes prevalence in South Africa [82], the provision of appropriate health supplies coupled with established screening protocol and referral system will ensure effective monitoring of individuals with diabetes. These measures will enable early detection and therapeutic management of blinding conditions and, consequently, reduce the burden of vision loss caused by diabetes.

The strength of this study lies in the fact that it uses the most recent nationally representative data of all ages, which provides adequate information on vision loss in South Africa. Furthermore, this study provides an appraisal of the efficiency of the existing structures and policies on eye care services to inform amendment and improvement in strategies regarding vision loss in South Africa. A major limitation of our study is that SANHANES-1; due to a large number of physical examinations and biomarker assessments being 
conducted did not perform a comprehensive ocular examination to determine the specific cause of vision loss. However, from the reported symptoms/signs, one could hypothesize or project the potential causes of vision loss. Again, it is worth mentioning that the subsample of participants whose vision was assessed is considerably smaller than the total sample. The subsample had a slightly higher proportion of female sex than the total sample, which may have introduced selection bias. Of note, another limitation of our study has to do with the use of relatively older research data. Nonetheless, this vital data has been the only population-based national health survey conducted in South Africa since 2011 that provides data on vision loss. Hence, our data primarily serves as a baseline for investigating vision loss and its associated factors in subsequent population-based studies in South Africa.

\section{Conclusion}

In summary, almost one in ten South Africans had vision loss. Older age, female sex, and having a previous diagnosis of diabetes were associated with higher odds of vision loss. On the contrary, living in Mpumalanga province, having secondary or tertiary education, and white ethnicity significantly reduced the odds of vision loss. These findings call on policymakers, government officials, and healthcare administrators to adopt strategies targeted at reducing barriers to eye care services such as improving accessibility, subsidizing the cost of health services, training of eye care professionals, and siting of eye care facilities in areas with low coverage of ocular health services. Furthermore, the findings suggest the need for health education and health promotion interventions that are targeted and tailored to groups of individuals that have a higher risk of vision loss, in order to increase awareness and promote eye care seeking behaviours. These strategies will promote early detection and management of blinding conditions and thereby, decrease the burden of vision loss in the country.

\section{Abbreviations}

AMD: Age-related Macular Degeneration; DFID: United Kingdom Department for International Development; HSRC: Human Sciences Research Council; REC: Research Ethics Committee; SANHANES: South African National Health and Nutrition Examination Survey; WHO: World Health Organization; HSS: Health System Strengthening; PVA: Presenting Visual Acuity

\section{Acknowledgements}

We thank all the experts that gave technical support in the SANHANES (as they are listed in the SANHANES-1 report). We also extend our gratitude to the community leaders and all the South Africans who participated in the survey.

\section{Authors' contributions}

The authors' contributions were as follows: conceptualization, K.O.A., R.S. and E.K.A.; methodology, K.O.A. and R.S.; formal analysis, R.S. and K.O.A.; writing-original draft preparation, K.O.A., E.K.A., R.S., A.K.A., E.A.M.; writing-review and editing, K.O.A., E.K.A., R.S., N.D., E.A.M., D.B.K., A.K.A., MA, and P.R.; supervision, K.O.A., D.B.K. and P.R. All authors have read and approved the manuscript.

\section{Funding}

No specific funding was received by authors for this work. However, the SANHANES-1 survey was funded by the South African Department of Health and the UK Department for International Development (DFID). The South African Department of Health and the UK DFID had no role in the design, data collection, analysis, interpretation of data, and in writing the manuscript for publication.

\section{Availability of data and materials}

The dataset(s) supporting the conclusions of this article is (are) available on request from the HSRC. The SANHANES data are available through registered access from the Human Sciences Research Council's (HSRC) data repository at http://curation.hsrc.ac.za/Datasets-XKAHAA.phtml.

\section{Ethics approval and consent to participate}

Ethical approval for the study was obtained from the Research Ethics Committee (REC) of the South African Human Sciences Research Council (HSRC) (REC number: 6/16/11/11). The study adhered to the tenets of the Declaration of Helsinki. Written informed consent/assent was obtained from all the survey participants. Written informed consent was obtained from a parent or guardian or caregiver for participants aged below 18 years. Access to the data was granted by the Human Sciences Research Council (HSRC), the institution who conducted the SANHANES survey. Furthermore, some of the authors are from the HSRC.

\section{Consent for publication}

Not applicable.

\section{Competing interests}

The authors declare that they have no competing interests.

\section{Author details}

${ }^{1}$ Department of Optometry and Visual Science, College of Science, Kwame Nkrumah University of Science and Technology, Kumasi, Ghana. ${ }^{2}$ Department of Ophthalmology and Visual Sciences, John A. Moran Eye Centre, University of Utah, Salt Lake City, Utah, USA. ${ }^{3}$ Department of Nutrition and Integrative Physiology, University of Utah, Salt Lake City, Utah, USA. ${ }^{4}$ Health \& Wellbeing, Human and Social Capabilities Division, Human Sciences Research Council, Cape Town, South Africa. ${ }^{5}$ Usher Institute for Population Health Sciences and Informatics, College of Medicine and Veterinary Medicine, University of Edinburgh, Edinburgh, UK. ${ }^{6}$ Faculty of Health Sciences, Nelson Mandela University, Port Elizabeth, South Africa.

Received: 14 July 2020 Accepted: 2 November 2020

Published online: 01 January 2021

\section{References}

1. Bourne RRA, Flaxman SR, Braithwaite T, Cicinelli MV, Das A, Jonas JB, et al. Magnitude, temporal trends, and projections of the global prevalence of blindness and distance and near vision impairment: a systematic review and meta-analysis. Lancet Glob Health. 2017;5(9):e888-97.

2. Flaxman SR, Bourne RRA, Resnikoff S, Ackland P, Braithwaite T, Cicinelli MV, et al. Global causes of blindness and distance vision impairment 1990-2020: a systematic review and meta-analysis. Lancet Glob Health. 2017:5(12): e1221-34.

3. Fricke TR, Tahhan N, Resnikoff S, Papas E, Burnett A, Ho SM, et al. Global prevalence of presbyopia and vision impairment from uncorrected presbyopia: systematic review, meta-analysis, and Modelling. Ophthalmology. 2018;125(10):1492-9.

4. Nyman SR, Gosney MA, Victor CR. Psychosocial impact of visual impairment in working-age adults. Br J Ophthalmol. 2010;94(11):1427-31.

5. Brown RL, Barrett AE. Visual impairment and quality of life among older adults: an examination of explanations for the relationship. J Gerontol Ser B Psychol Sci Soc Sci. 2011;66(3):364-73.

6. Cahill MT, Banks AD, Stinnett SS, Toth CA. Vision-related quality of life in patients with bilateral severe age-related macular degeneration. Ophthalmology. 2005;112(1):152-8.

7. Evans JR, Fletcher AE, Wormald RP. Depression and anxiety in visually impaired older people. Ophthalmology. 2007;114(2):283-8. 
8. van der Aa HPA, Comijs HC, Penninx BWJH, van Rens GHMB, van Nispen RMA. Major depressive and anxiety disorders in visually impaired older adults. Invest Ophthalmol Vis Sci. 2015;56(2):849-54.

9. Warren DH. Blindness and children: an individual differences approach. Cambridge: Cambridge University Press; 1994.

10. Rainey L, Elsman EBM, van Nispen RMA, van Leeuwen LM, van Rens $G$. Comprehending the impact of low vision on the lives of children and adolescents: a qualitative approach. Qual Life Res. 2016;25(10):2633-43.

11. Augestad LB. Self-concept and self-esteem among children and young adults with visual impairment: a systematic review. Cogent Psychol. 2017; $4(1): 1-13$

12. Ethan D, Basch CE. Promoting healthy vision in students: progress and challenges in policy, programs, and research. J Sch Health. 2008;78(8):411-6.

13. Toledo CC, Paiva AP, Camilo GB, Maior MR, Leite IC, Guerra MR. Early detection of visual impairment and its relation to academic performance. Revista da Associacao Med Bras (1992). 2010;56(4):415-9.

14. Oh H-K, Ozturk MA, FMJRV K. Physical activity and social engagement patterns during physical education of youth with visual impairments. Rehab Educ Blindness Vis Impairment. 2004;36:39-48.

15. Eckert KA, Carter MJ, Lansingh VC, Wilson DA, Furtado JM, Frick KD, et al. A simple method for estimating the economic cost of productivity loss due to blindness and moderate to severe visual impairment. Ophthalmic Epidemiol. 2015;22(5):349-55.

16. Smith TS, Frick KD, Holden BA, Fricke TR, Naidoo KS. Potential lost productivity resulting from the global burden of uncorrected refractive error. Bull World Health Organ. 2009;87(6):431-7.

17. Song P, Wang H, Theodoratou E, Chan KY, Rudan I. The national and subnational prevalence of cataract and cataract blindness in China: a systematic review and meta-analysis. J Glob Health. 2018;8(1):010804.

18. Tham YC, Li X, Wong TY, Quigley HA, Aung T, Cheng CY. Global prevalence of glaucoma and projections of glaucoma burden through 2040: a systematic review and meta-analysis. Ophthalmology. 2014;121(11):2081-90.

19. Wong WL, Su X, Li X, Cheung CM, Klein R, Cheng CY, et al. Global prevalence of age-related macular degeneration and disease burden projection for 2020 and 2040: a systematic review and meta-analysis. Lancet Glob Health. 2014;2(2):e106-16.

20. Chen M, Yu X, Xu J, Ma J, Chen X, Chen B, et al. Association of Gene Polymorphisms with primary open angle glaucoma: a systematic review and meta-analysis. Invest Ophthalmol Vis Sci. 2019;60(4):1105-21.

21. Daiger SP, Bowne SJ, Sullivan LS. Perspective on genes and mutations causing retinitis pigmentosa. Arch Ophthalmol (Chicago, III : 1960). 2007; 125(2):151-8.

22. Thornton J, Edwards R, Mitchell P, Harrison RA, Buchan I, Kelly SP. Smoking and age-related macular degeneration: a review of association. Eye (London, England). 2005;19(9):935-44.

23. Ye J, He J, Wang C, Wu H, Shi X, Zhang H, et al. Smoking and risk of agerelated cataract: a meta-analysis. Invest Ophthalmol Vis Sci. 2012:53(7):388595.

24. Song $P$, Wang J, Wei W, Chang X, Wang M, An L. The prevalence of vitamin a deficiency in Chinese children: a systematic review and Bayesian metaanalysis. Nutrients. 2017;9:12.

25. Cassel CK. Successful aging. How increased life expectancy and medical advances are changing geriatric care. Geriatrics. 2001:56(1):35-9.

26. Leske MC, Wu SY, Hennis A, Honkanen R, Nemesure B. Risk factors for incident open-angle glaucoma: the Barbados eye studies. Ophthalmology. 2008;115(1):85-93.

27. Cockburn N, Steven D, Lecuona K, Joubert F, Rogers G, Cook C, et al. Prevalence, causes and socio-economic determinants of vision loss in Cape Town, South Africa. PLoS One. 2012;7(2):e30718.

28. Budenz DL, Bandi JR, Barton K, Nolan W, Herndon L, Whiteside-de Vos J, et al. Blindness and visual impairment in an urban west African population: the Tema eye survey. Ophthalmology. 2012;119(9):1744-53.

29. Pascolini D, Mariotti SP. Global estimates of visual impairment: 2010. Br J Ophthalmol. 2012;96(5):614-8.

30. Gilbert S, Patel D. Recruiting and distributing eye health workers. Community Eye Health. 2018;31(102):45-7.

31. South African Department of Health. National Guideline-Prevention of blindness in South Africa. Pretoria: DOH; 2002.

32. Naidoo KS, Sweeney D, Jaggernath J, Holden B. A population-based study of visual impairment in the lower Tugela health district in KwaZulu Natal, South Africa. Afr Vis Eye Health. 2013;1:9.
33. Naidoo K, Kempen JH, Gichuhi S, Braithwaite T, Casson RJ, Cicinelli MV, et al. Prevalence and causes of vision loss in sub-Saharan Africa in 2015: magnitude, temporal trends and projections. Br J Ophthalmol. 2020;1:1-11.

34. Shisana O, Labadarios D, Rehle T, Simbayi L, Zuma K, Dhansay A, et al. South African National Health and nutrition examination survey (SANHAN ES-1) Cape Town; 2013.

35. Statistics South Africa. Mid-year population estimates 2019. Pretoria: Statistics South Africa; 2019.

36. Tielsch JM, Javitt JC, Coleman A, Katz J, Sommer A. The prevalence of blindness and visual impairment among nursing home residents in Baltimore. N Engl J Med. 1995;332(18):1205-9.

37. Statistics South Africa. Census, 2011 census in brief. Pretoria: Statistics South Africa; 2012.

38. Abdull MM, Sivasubramaniam S, Murthy GVS, Gilbert C, Abubakar T, Ezelum

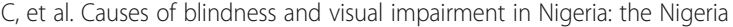
National Blindness and visual impairment survey. Invest Ophthalmol Vis Sci. 2009:50(9):4114-20.

39. Abou-Gareeb I, Lewallen S, Bassett K, Courtright P. Gender and blindness: a meta-analysis of population-based prevalence surveys. Ophthalmic Epidemiol. 2001;8(1):39-56.

40. Akano OF. Vision health disparities in blindness and visual impairment in Nigeria: a review of the Nigerian National Blindness and visual impairment survey. J African Vis Eye Health. 2017;76:1.

41. Maake MM, Oduntan OA. Prevalence and causes of visual impairment in patients seen at Nkhensani hospital eye clinic, South Africa. Afr J Prim Health Care Fam Med. 2015;7(1):1-6.

42. Naidoo KS, Jaggernath J, Ramson P, Chinanayi F, Zhuwau T, Øverland L. The prevalence of self-reported vision difficulty in economically disadvantaged regions of South Africa. Afr J Disabil. 2015:4(1):136.

43. Varma R, Macias GL, Torres M, Klein R, Pena FY, Azen SP, et al. Biologic risk factors associated with diabetic retinopathy: the Los Angeles Latino eye study. Ophthalmology. 2007;114(7):1332-40.

44. Akuffo KO, Asare AK, Sewpaul R, Dukhi N, Kumah DB, Agyei-Manu E, et al. Eye care utilization among diabetics in the south African National Health and nutrition examination survey (SANHANES-1): a cross-sectional study. BMC Res Notes. 2020;13(1):407.

45. Malhotra S, Vashist P, Kalaivani M, Gupta N, Senjam SS, Rath R, et al. Prevalence and causes of visual impairment amongst older adults in a rural area of North India: a cross-sectional study. BMJ Open. 2018;8(3):e018894.

46. Wagner LD, Rein DB. Attributes associated with eye care use in the United States: a meta-analysis. Ophthalmology. 2013;120(7):1497-501.

47. Varma R, Kim JS, Burkemper BS, Wen G, Torres M, Hsu C, et al. Prevalence and causes of visual impairment and blindness in Chinese American adults: the Chinese American eye study. JAMA Ophthalmol. 2016:134(7):785-93.

48. Katibeh M, Pakravan M, Yaseri M, Pakbin M, Soleimanizad R. Prevalence and causes of visual impairment and blindness in Central Iran; the Yazd eye study. J Ophthalmic Vis Res. 2015;10(3):279-85.

49. Stevens GA, White RA, Flaxman SR, Price H, Jonas JB, Keeffe J, et al. Global prevalence of vision impairment and blindness: magnitude and temporal trends, 1990-2010. Ophthalmology. 2013:120(12):2377-84.

50. World Health $\mathrm{O}$. Global initiative for the elimination of avoidable blindness : action plan 2006-2011. Geneva: World Health Organization; 2007.

51. Austad SN. Why women live longer than men: sex differences in longevity. Gender Med. 2006:3(2):79-92.

52. Ginter E, Simko V. Women live longer than men. Bratisl Lek Listy. 2013; 114(2):45-9.

53. Karastergiou K, Smith SR, Greenberg AS, Fried SK. Sex differences in human adipose tissues - the biology of pear shape. Biol Sex Differ. 2012;3(1):13.

54. Achigbu EO, Dike KC, Uwakwem AC, Ogborogu EU, Nkwogu VC. Ocular morbidity in rural communities in Imo state south East Nigeria. J Open J Ophthalmol. 2016, 06(03):184-90.

55. Courtright $P$, Lewallen $S$. Why are we addressing gender issues in vision loss? Community Eye Health. 2009;22(70):17-9.

56. Zainal M, Ismail SM, Ropilah AR, Elias H, Arumugam G, Alias D, et al Prevalence of blindness and low vision in Malaysian population: results from the national eye survey 1996. Br J Ophthalmol. 2002; 86(9):951-6.

57. Harris B, Goudge J, Ataguba JE, McIntyre D, Nxumalo N, Jikwana S, et al. Inequities in access to health care in South Africa. J Public Health Policy. 2011;32(Suppl 1):S102-23. 
58. Mathee A, de la Rey A, Swart A, Plagerson S, Naicker N. 'Urban insight': a high level of undiagnosed need reflects limited access to and availability of eye-care services in South Africa. South Afr Med J. 2014;104(6):407-8.

59. Gilbert CE, Murthy GV, Sivasubramaniam S, Kyari F, Imam A, Rabiu MM, et al Couching in Nigeria: prevalence, risk factors and visual acuity outcomes. Ophthalmic Epidemiol. 2010;17(5):269-75.

60. O'Donnell O. Access to health care in developing countries: breaking down demand side barriers. J Cadernos de Saúde Pública. 2007;23:2820-34.

61. Murthy G, Gupta S, Ellwein LB, Munoz SR, Bachani D, Dada VJO. A population-based eye survey of older adults in a rural district of Rajasthan: I. Central Vis Impairment Blindness Cataract Surg. 2001;108(4):679-85.

62. Nirmalan PK, Thulasiraj RD, Maneksha V, Rahmathullah R, Ramakrishnan R, Padmavathi A, et al. A population based eye survey of older adults in Tirunelveli district of South India: blindness, cataract surgery, and visual outcomes. Br J Ophthalmol. 2002:86(5):505-12.

63. Hu J-Y, Yan L, Chen Y-D, Du X-H, Li T-T, Liu D-A, et al. Population-based survey of prevalence, causes, and risk factors for blindness and visual impairment in an aging Chinese metropolitan population. Int J Ophthalmol. 2017;10(1):140-7.

64. Xu L, Cui T, Yang H, Hu A, Ma K, Zheng Y, et al. Prevalence of visual impairment among adults in China: the Beijing eye study. Am J Ophthalmol. 2006;141(3):591-3.

65. Shrestha MK, Guo CW, Maharjan N, Gurung R, Ruit S. Health literacy of common ocular diseases in Nepal. BMC Ophthalmol. 2014;14:2-2.

66. Lawn JE, Kinney M. Health in South Africa: an executive summary for the lancet series: the lancet; 2009

67. Lecuona K, Cook C. South Africa's cataract surgery rates: why are we not meeting our targets? South Afr Med J. 2011;101(8):510-2.

68. Statistics South Africa. Poverty trends in South Africa: An examination of absolute poverty between 2006 and 2011. Pretoria: Statistics South Africa; 2014.

69. Lilian RR, Railton J, Schaftenaar E, Mabitsi M, Grobbelaar CJ, Khosa NS, et al. Strengthening primary eye care in South Africa: an assessment of services and prospective evaluation of a health systems support package. PLoS One. 2018;13(5):1-16.

70. Ramke J, Zwi AB, Palagyi A, Blignault I, Gilbert CE. Equity and blindness: closing evidence gaps to support universal eye health. Ophthalmic Epidemiol. 2015;22(5):297-307.

71. Sacharowitz HS. Visual impairment in South Africa: achievements and challenges. Afr Vis Eye Health. 2005:64(4):139-49.

72. Freeman EE, Roy-Gagnon MH, Samson E, Haddad S, Aubin MJ, Vela C, et al. The global burden of visual difficulty in low, middle, and high income countries. PLoS One. 2013;8(5):e63315.

73. Lewallen S, Courtright P. Blindness in Africa: present situation and future needs. Br J Ophthalmol. 2001;85(8):897-903.

74. Naipal S, Rampersad N. A review of visual impairment. J African Vis Eye Health. 2018;77(1):a393

75. Jaggernath J, Øverland L, Ramson P, Kovai V, Chan VF, Naidoo KSJH. Poverty and eye health. Health. 2014;6:1849-60.

76. Sithole HL. A situational analysis of ocular health promotion in the south African primary health-care system. Clin Exp Optom. 2017;100(2):167-73.

77. Lilian RR, Railton J, Schaftenaar E, Mabitsi M, Grobbelaar CJ, Khosa NS, et al. Strengthening primary eye care in South Africa: an assessment of services and prospective evaluation of a health systems support package. PLoS One. 2018;13(5):e0197432

78. Webb EM, Rheeder P, Van Zyl DG. Diabetes care and complications in primary care in the Tshwane district of South Africa. Primary Care Diab. 2015;9(2):147-54

79. Stokes A, Berry KM, McHiza Z, Parker W-A, Labadarios D, Chola L, et al. Prevalence and unmet need for diabetes care across the care continuum in a national sample of south African adults: evidence from the SANHANES-1, 2011-2012. PLoS One. 2017;12(10):e0184264.

80. Khan T, Bertram MY, Jina R, Mash B, Levitt N, Hofman K. Preventing diabetes blindness: cost effectiveness of a screening programme using digital nonmydriatic fundus photography for diabetic retinopathy in a primary health care setting in South Africa. Diabetes Res Clin Pract. 2013;101(2):170-6.

81. Tu KL, Palimar P, Sen S, Mathew P, Khaleeli A. Comparison of optometry vs digital photography screening for diabetic retinopathy in a single district. Eye (London, England). 2004;18(1):3-8
82. Bradshaw D, Norman R, Pieterse D, Levitt NS. Estimating the burden of disease attributable to diabetes in South Africa in 2000. South Afr Med J. 2007;97(8 Pt 2):700-6.

\section{Publisher's Note}

Springer Nature remains neutral with regard to jurisdictional claims in published maps and institutional affiliations.
Ready to submit your research? Choose BMC and benefit from:

- fast, convenient online submission

- thorough peer review by experienced researchers in your field

- rapid publication on acceptance

- support for research data, including large and complex data types

- gold Open Access which fosters wider collaboration and increased citations

- maximum visibility for your research: over $100 \mathrm{M}$ website views per year

At BMC, research is always in progress.

Learn more biomedcentral.com/submissions 